\title{
Student's Communication Activity in Small Group Learning
}

\author{
Ligita Stramkale Dr. paed. \\ University of Latvia, Latvia \\ ligita.stramkale@lu.lv
}

\begin{abstract}
This paper analyzes students' communication activity in small-group learning. The study identified four types of learning groups: mixed-achievement group, unmixed-achievement group, mixedgender group and unmixed-gender group. The aim of the study is to define the factors associated with the communication activity in each type of learning groups. In order to achieve this aim, the concept of communication activity and previous studies on communications in small-group learning were theoretically analyzed. In the empirical study, the communication activity in sixteen learning groups was analyzed. The study was carried out in Latvian X primary school during the period from February 2017 to May 2017, with a randomly selected sample of 58 participants $(\mathrm{N}=58)$ aged 12-14 years. In order to determine the factors affecting communication activity among the students while they are working in different types of small-group learning, the students were asked to fulfill self-assessment questionnaire at the end of the lesson. In the study reported here, three complex factors or dimensions that shape the communication activity were identified: engagement in the learning group, activity/passivity and success/failure. The study determined that the factors affecting communication activity in the mixedachievement group and in the unmixed-achievement group can be both similar and different. A common factor of the communication activity in both types of learning groups is asking for help and/or offering support for group members. However, the communication activity in the mixed-achievement group is associated with the opportunity to express oneself creatively, and with making a significant contribution to the work of the group, but the communication activity in the unmixed-achievement group is determined by the fear of failure or the orientation towards success. It is also determined several factors of communication activity that affect the student's activity or passivity in the mixed-gender group. The results of the study provide an opportunity to better understand the benefits of different group compositions within the context of communication activity.
\end{abstract}

Keywords: communication activity, small-group learning, a primary school student, school education.

\section{Introduction}

Group work in education is a teaching method and organization form that provides cooperation, interaction, and communication to accomplish a joint task. The idea of learning in groups has already been mentioned by J. Dewey at the beginning of the $20^{\text {th }}$ century (Dewey, 2015). Nowadays, several studies have been carried out on the benefits of implementing group work in school learning process. For example, G. Schellenberg (Schellenberg et al., 2015) and his colleagues have found that children in $3^{\text {rd }}$ and $4^{\text {th }}$ grade, who are playing music in groups, have the opportunity to develop their prosocial skills. A study conducted by R. Gillies (Gillies, 2003) proves that structured learning in small groups promotes learning and socialization. He believes that students in group learning are more motivated to achieve high results than learning individually. Also, H. Shachar and S. Fischer in their study emphasize the positive impact of learning in groups on the student's motivation to achieve higher results (Shachar, Fischer, 2004). Despite the many benefits of using group work, the researchers have discovered some disadvantages to be considered. It is found that teachers are having some difficulties with preparing and structuring the group work, and in planning the suitable time to accomplish a certain task in the group (Gillies, Boyle, 2010). N. Webb's study proved that the role of a teacher is essential for students learning in small groups (Webb, 2009). The effectiveness of small-group learning is largely dependent on communication activity among primary school students. Passivity in small-group is mostly the reason why the learning group could not perform a given task successfully.

The concept "activity" is translated from Latin as a state of being active, briskness or liveliness (Harper, 2010). The meaning of activity in Cambridge dictionary is the situation in which a lot of things are happening, or people are moving around, or the work of a group to achieve an aim (Cambridge Dictionary, 2018). Activity is mostly associated with something that people do because they enjoy it, or it is interesting (Robinson, Davidson, 1999). The concept "activity" has a varied explanation, which is based on the cognition of a particular field of science. For example, in the encyclopedia of values, 
activity is interpreted as a human action, which includes both physical and mental actions. Activity is triggered by external or internal motivation (Enzyklopadie der Werte..., 2018). In the psychology, activity is explained as ability in the context of personality (Leontyev, 2009), it must be analyzable in its dynamics and transformations, in its evolution and historical change (Engeström, 1987), it is related to good behavior and positive feelings (Fredricks, 2014). Meanwhile, the behavior is associated with constant choice and decision making. Lots of decisions should be made in learning group in order to perform a task successfully. The Russian researcher J. Feygenberg believes that a decision can be made in four ways to perform a task successfully. The first way is a correct answer with a confidence in the decision. The second way is a correct answer without a confidence in the decision. The third way is a wrong answer without a confidence in the decision. The fourth way is a wrong answer with a confidence in the decision (Feygenberg, 2014). Decisions can be made by compromise or consensus. Polarization is also possible when everyone stays at his or her point of view and cannot find a common solution. In the psychology, it is considered that making a joint decision is more difficult if the members of the group have a different value system, interests, and abilities (Corsini, Auerbach, 1998).

Three phenomena are identified by studying the concept "activity". First of all, it may be a concrete individual action. Secondly, it may be a situation that is the opposite of passivity. The activity as a situation is based on the needs and interests of a primary school student and is expressed as internal readiness for action. Thirdly, it is an initiative to do and promote the occurrence of certain things. To make that happen, it is necessary to encourage the student in order to be fascinated with the work to be done. All of these three phenomena have one thing in common, that the activity associated with vigorousness and mobilization. In education, activity related to learning by doing and purposefulness. The student's activity is purposeful, if it is aimed at fulfilling the task successfully, which in this study is reflected in the dimension of engagement, and it is characterized by a degree of intensity, which is reflected in the dimension of activity and passivity.

There are several forms and types of student's activity. W. Bion has developed several forms of group activity. The first form of group activity is dependent on the leader of the group and his/her support for other group members. The second form of group activity is characterized by attacking each other or the avoidance of each other. The third form of group activity is aimed at one purpose to be achieved (Bion, 2004). We often face several forms of activity every day, such as communication activity, physical activity, mental activity, cognitive activity and creative activity. In the study reported here, the student's communication activity in small-group learning was analyzed. The communication activity is understood within the framework of this study as an attitude characterized by energetic self-acting and aimed at achieving a goal.

The aim of the study is to define the factors associated with communication activity in mixedachievement groups and unmixed- achievement groups, as well as in mixed-gender groups and unmixed-gender groups.

\section{Methodology}

The study was carried out in Latvian X primary school during the period from February 2017 to May 2017. The study sample comprised 58 participants $(\mathrm{N}=58)$ aged $12-14$ years, 37 girls and 21 boys, randomly selected and generalized to the target population (12-14 years old primary school students). Each participant was given a code, for example, G1 is given for the girls and B1for the boys. The communication activity was analyzed in 16 learning groups. Seven groups contain three students each, eight groups contain four students each and one group contains five students each. Each group has a code in the study. The first symbol in the code is the title of the school subject, the second symbol is the grade, the third symbol is group number in the sequence and the fourth symbol indicates whether the learning group is unmixedgender (UMG) or mixed-gender (MG). For example, the code could be G.8.1.UMG or M.7.3.MG.

Eight learning groups were unmixed-achievement groups and have got the following cods (G.8.1.UAG; G.8.4.UAG; S.6.1.UAG; S.6.3.UAG; M.7.3.UAG; V.7.1.UAG; V.7.2.UAG; V.7.4.UAG), and eight learning groups were mixed- achievement groups and have got the following cods (G.8.2.MAG; G.8.3.MAG; M.7.1MAG; M.7.2.MAG; M.7.4.MAG; S.6.2.MAG; S.6.4.MAG; V.7.3.MAG). Five learning groups were unmixed-gender groups and have got the following codes (G.8.1.UMG; G.8.2.UMG; G.8.3.UMG; G.8.4.UMG; V.7.4.UMG), and eleven learning groups were mixed-gender groups and have got the following codes (S.6.1.MG; S.6.2.MG; S.6.3.MG; S.6.4.MG; M.7.1.MG; 
M.7.2.MG; M.7.3.MG; M.7.4.MG; V.7.1.MG; V.7.2.MG; V.7.3.MG). Four unmixed-gender groups contain girls only and one unmixed-gender group contains boys only.

The following research questions will be answered by the study.

- What are the factors associated with communication activity in the unmixed-achievement group and the in mixed-achievement group?

- What are the factors associated with communication activity in the unmixed-gender group and in the mixed-gender group?

- Is there a relationship between students` communication activities and the assessment of achievement?

An original self-assessment questionnaire was conducted to determine the communication activity in small-group learning. The questionnaire consisted of several statements, which should be assessed by each student using a six-point Likert scale. For data processing, the answer variants were transcoded into numbers: 6 - fully agree, 5 - agree, 4 - partially agree, 3 - partially disagree, 2 - disagree and 1 fully disagree.

As a result of factor analysis, the study identified three complex factors or dimensions that shape communication activity in small-group learning. The first dimension is the activity or passivity of the members in the learning groups, the second one is the students' orientation toward success or failure and the third dimension is the students' engagement in the learning groups. The level of each dimension was indicated by three statements (Table 1).

Levels and indicators of study dimensions

Table 1

\begin{tabular}{|c|c|c|}
\hline Study dimensions & Level & Indicator \\
\hline \multirow[t]{3}{*}{ Activity/passivity } & High & Ask for help from group members and support them \\
\hline & Middle & Sometimes ask for help and sometimes support group members \\
\hline & Low & Do not ask for help and do not support group members \\
\hline \multirow[t]{3}{*}{ Success/failure } & High & Dominate and active \\
\hline & Middle & Sometimes dominate and sometimes active \\
\hline & Low & Committed \\
\hline \multirow[t]{3}{*}{$\begin{array}{l}\text { Engagement in a } \\
\text { learning group }\end{array}$} & High & $\begin{array}{l}\text { The action is focused on the task, always creative and give a } \\
\text { contribution to the group's work }\end{array}$ \\
\hline & Middle & $\begin{array}{l}\text { The action is partly focused on the task, sometimes is creative } \\
\text { and has a partial contribution to the group's work }\end{array}$ \\
\hline & Low & $\begin{array}{l}\text { The action is not focused on the task, there is a shortage of } \\
\text { creativity and does not contribute to the group's work }\end{array}$ \\
\hline
\end{tabular}

Each level of the study dimension was determined by a certain scaled score. The high level is from 4.34 to 6.00 points, the middle level is from 2.67 to 4.33 points and the low level is from 1 to 2.66 points. As a result of documents analysis, the assessment of each student's achievement in a concrete subject was defined.

Primary school students' communication activity in learning groups was analyzed during lessons on four school subjects - geography (code G), social sciences (code S), music (code M) and visual arts (code V). R. Fisher (Fisher, 2014) suggests that different types of tasks should be given to learning groups, such as interpretative discussion, problem-solving tasks or production tasks. The study reported here, in all subjects, the learning groups were given the same types of tasks, which are production tasks. The primary school students were divided into learning groups by subject teachers following the principle of randomness.

After group work, each respondent was given a self-assessment questionnaire to be filled without limited time. The questionnaire was not anonym. The respondents could ask any question to the questionnaire creator just in case of ambiguity or misunderstanding. The questionnaire was held in frontal view. 
In quantitative data analysis, the Statistical Package for Social Sciences (SPSS software version 22) is used. The factor analysis is used to determine the mutual relations of questionnaire statements and distribute the complex factors. Cronbach's Alpha is used to determine and measure the internal consistency reliability of the complex factors or dimensions. Student's T-Test is used to check whether there is a statistically significant difference between the arithmetic means of the variables (unmixedgender group and mixed-gender group; unmixed-achievement group and mixed-achievement group).

The Bivariate Pearson Correlation is used to measure the strength and direction of linear relationships between the variables. The correlation coefficient has statistically significant sigma of 0.01 and 0.05 . The mean (M), standard deviation (SD) and standard deviation error (SE) of each statement and study dimension for the 16 learning groups were calculated.

\section{Results and discussion}

Three study dimensions were used to determine communication activity in small-group learning: engagement in a learning group, activity/passivity and success/failure. One of the study questions is to find out what factors associated with students' communication activity in the unmixed-achievement group and in the mixed-achievement group. The results are reflected in Table 2.

Table 2

Communication activity in unmixed and mixed-achievement groups

\begin{tabular}{|l|l|c|c|c|c|c|c|}
\hline \multicolumn{2}{|c}{ Study dimensions } & \multicolumn{3}{c|}{$\begin{array}{c}\text { Unmixed-achievement groups } \\
(\mathbf{n = 2 9 )}\end{array}$} & \multicolumn{3}{c|}{$\begin{array}{c}\text { Mixed-achievement groups } \\
(\mathbf{n = 2 9})\end{array}$} \\
\cline { 3 - 8 } \multicolumn{2}{|c|}{} & $\mathrm{M}$ & SD & SE & M & SD & SE \\
\hline Engagement in & 1. & 4.97 & 1.02 & 0.19 & 4.71 & 0.90 & 0.17 \\
learning group* & 2. & 4.48 & 0.99 & 0.18 & 4.54 & 1.35 & 0.25 \\
& 3. & 4.76 & 0.91 & 0.17 & 4.71 & 0.85 & 0.16 \\
\hline \multirow{2}{*}{ Activity/passivity** } & 4. & 3.86 & 1.38 & 0.26 & 3.57 & 1.17 & 0.22 \\
& 5. & 2.45 & 1.43 & 0.27 & 2.64 & 1.29 & 0.24 \\
& 6. & 4.20 & 1.54 & 0.29 & 4.25 & 1.35 & 0.26 \\
\hline \multirow{2}{*}{ Success/failure*** } & 7. & 3.76 & 1.33 & 0.25 & 3.96 & 1.14 & 0.22 \\
& 8. & 4.00 & 0.80 & 0.15 & 4.39 & 1.07 & 0.20 \\
& 9. & 4.76 & 0.95 & 0.18 & 4.89 & 1.13 & 0.21 \\
\hline
\end{tabular}

* Engagement in learning group: 1. Contribution to group work is important 2. Creative engagement in fulfilling a task. 3. The action aimed at fulfilling a task.

** Activity/passivity: 4. Listening more than speaking 5. Passive in group work. 6. Support and help group members.

*** Success/failure 7. Fear of failure or oriented to success 8 . Being committed or dominated in group 9 . Activity or passivity.

Students, engagement in a learning group is one of the study dimensions that shape communication activity. It is characterized by an action aimed at fulfilling a certain task successfully, creative expression and contribution to group work. The internal consistency reliability is high for this variable $(a=0.657)$. The learning process is more effective if the student focuses on fulfilling the given task during the lesson. However, the communication activity among students in small-group learning may deviate from the objective of the task. Therefore, it is essential that each teacher should know and understand the factors affecting students' communication activity in small-group learning in order to encourage students to aim at fulfilling a certain task successfully. The study found that in both unmixed-achievement groups $(\mathrm{r}=0.372 ; \mathrm{p}<0.05)$ and mixed-achievement groups $(\mathrm{r}=0.395 ; \mathrm{p}<0.05)$, the students' communication activity could be aimed at fulfilling a task by giving the opportunity to express oneself creatively in group work.

Communication activity in the mixed-achievement group, which aimed at performing a task, is also determined by the degree of success in a concrete subject $(r=0.500 ; p<0.01)$. It was found that primary school students with lower degrees of success are more cautious about engaging in the work of learning group because they think that they will not be able to deal with the given task $(r=0.492 ; \mathrm{p}<0.01)$. As a result of that, the students with lower degrees tend to be more committed $(r=0.470 ; p<0.05)$ in mixed- 
achievement groups and be always passive $(r=0.543 ; \mathrm{p}<0.01)$. In order to enable all students to be active and make an effective contribution to the work of the mixed-achievement group, more support and assistance are needed $(r=0.398 ; \mathrm{p}<0.05)$.

In the unmixed-achievement group, the degree of success plays a significant role in students' creative expression in learning group $(\mathrm{r}=0.490 ; \mathrm{p}<0.01)$. A high degree of success in a concrete subject provides the students with confidence in their abilities. On the one hand, those students, who are convinced of their abilities, as well as more oriented towards success than failure, are less committed to the members of learning group $(\mathrm{r}=0.451 ; \mathrm{p}<0.01)$ and their contribution to the work of the learning group is significant $(\mathrm{r}=0.330$; $\mathrm{p}<0,01)$. On the other hand, those students, who are more committed to the group members than take the initiative and dominate, could not make a significant contribution to the work of group $(r=0.322 ; p<0.01)$. If students do not like to be a member of learning group, it will be very difficult to engage them in performing a certain task. The study identified two factors that affect the students' wiliness to learn in small-group; the opportunity to acquire new knowledge and skills $(r=0.486 ; \mathrm{p}<0.01)$ and good discipline in the group $(r=0.369 ; \mathrm{p}<0.01)$.

Table 2 shows the statistical mean (M), the standard deviation (SD) and standard deviation error (SE) of all study dimensions in unmixed-achievement groups and mixed-achievement groups. The internal consistency of the average for both unmixed and mixed-achievement groups in all study dimensions is high enough $(\mathrm{a}=0.456)$. This will make it possible to compare students' communication activities in unmixed-achievement groups, as well as in mixed-achievement groups. The primary school students' engagement in both learning groups is at a high level, however, the dimension of activity or passivity indicates a middle level in both groups. The mean scores of the degree of success in both groups are the same as well. But a significant difference was found in the dimension of the orientation towards success or failure $(\mathrm{a}<0.05)$. The unmixed-achievement groups have a middle level, but the mixed- achievement groups have a high level. This means that the learning groups, which contain students with a high, optimal and sufficient degree of success, are less focused on the possibility that they will not able to deal with the given task and perform it successfully.

In the study was defined a question, which aimed to clarify the factors that affecting communication activity in mixed-gender groups and unmixed-gender groups. In this study, only mixed-gender groups were analyzed $(a=0.590)$, because the internal consistency reliability of the study data obtained for unmixed-gender groups was very low. This may be due to an insufficient number of the unmixed-gender groups, which are included in the study. Both boys and girls are learning in mixed-gender groups. The study found that student's engagement in the mixed-gender group is directly related to his/her activity or passivity. The study dimension "activity or passivity" is characterized by speaking or listening, as well as offering support to the group members or being passive. The internal consistency of this dimension indicates a high degree of reliability $(\mathrm{a}=0.576)$. The study determined that there is a correlation between the indicators, which characterize the students' engagement in learning groups and the indicators, which characterize their activity or passivity $(\mathrm{r}=0.402 ; \mathrm{p}<0.01)$. The activity of each student in learning group is dependent mostly on the solidarity among group members, the more the students are passive in a learning group, the less they will be able to work together to accomplish a joint task. If the student is passive in the mixed-gender group, then he/her will not offer a support for other group members $(r=0.336 ; p<0.05)$. The study determined several factors affect the student's activity or passivity in mixed-gender group, such as the opportunity to be creative $(r=0.479 ; \mathrm{p}<0.01)$ and to be a leader $(\mathrm{r}=0.418 ; \mathrm{p}<0.01)$, as well as the opportunity to give a significant contribution to the work of group $(r=0.418 ; p<0.01)$ and to be oriented towards fulfilling a certain task successfully $(r=0.336 ; p<0,05)$.

Table 3 shows the statistical mean (M), standard deviation (SD) and standard deviation error (SE) of all study dimensions in unmixed-gender groups and mixed-gender groups. Primary school students' engagement in mixed-gender groups is at a high level and the average degree of success is high as well, but the activity or passivity indicates a middle level. The orientation towards success or failure in the mixed-gender groups is at a middle level, but in the unmixed-gender group is high. By using Student's TTest, it is determined that there is no statistically significant difference between the average scores of unmixed-gender groups and mixed-gender groups. Therefore, in order to compare the study dimensions and determine whether there are statistical regularities between unmixed-gender groups and mixed-gender groups, it is necessary to increase the number of unmixed-gender groups and repeat the study again. 
Table 3

Communication activity in mixed and unmixed- gender groups

\begin{tabular}{|c|c|c|c|c|c|c|c|}
\hline \multicolumn{2}{|l|}{ Study dimensions } & \multicolumn{3}{|c|}{$\begin{array}{l}\text { Mixed-gender groups } \\
\qquad(\mathrm{n}=41)\end{array}$} & \multicolumn{3}{|c|}{$\begin{array}{l}\text { Unmixed-gender groups } \\
\qquad(\mathrm{n}=17)\end{array}$} \\
\hline & & $\mathrm{M}$ & $\mathrm{SD}$ & SE & $\mathrm{M}$ & $\mathrm{SD}$ & SE \\
\hline \multirow{3}{*}{$\begin{array}{l}\text { Engagement in learning } \\
\text { group* }\end{array}$} & 1. & 4.78 & 1.04 & 0.16 & 5.00 & 0.71 & 0.17 \\
\hline & 2. & 4.44 & 1.30 & 0.20 & 4.65 & 0.70 & 0.17 \\
\hline & 3. & 4.73 & 0.92 & 0.14 & 4.82 & 0.81 & 0.12 \\
\hline \multirow{3}{*}{ Activity/passivity** } & 4. & 3.80 & 1.40 & 0.21 & 3.41 & 0.94 & 0.23 \\
\hline & 5 . & 2.78 & 1.41 & 0.22 & 1.94 & 0.97 & 0.23 \\
\hline & 6. & 4.10 & 1.46 & 0.23 & 4.57 & 1.33 & 0.32 \\
\hline \multirow{3}{*}{ Success/failure $* * *$} & 7. & 3.78 & 1.15 & 0.18 & 4.18 & 1.47 & 0.36 \\
\hline & 8. & 4.17 & 1.00 & 0.16 & 4.35 & 0.93 & 0.23 \\
\hline & 9. & 4.73 & 1.07 & 0.17 & 5.06 & 0.90 & 0.22 \\
\hline
\end{tabular}

* Engagement in learning group: 1. Contribution to group work is important. 2. Creative engagement in fulfilling a task. 3. The action aimed at fulfilling a task.

** Activity/passivity: 4. Listening more than speaking 5. Passive in group work. 6. Support and help group members.

*** Success/failure 7. Fear of failure or oriented to success 8 . Being committed or dominated in group 9. Activity/passivity.

Several researchers have compared learning in different gender and achievement groups in their studies. For example, R. Gillies (Gillies, 2004) have conducted a study that identified the impact of cooperative learning on students, who studied in structured and unstructured cooperative groups. The students studied in different gender and achievement groups. The study included that students, who studied in structured groups, are more likely to work together, help each other and offer support to each other. The structured group is characterized by social responsibility for learning more than the unstructured one. S. Farivar (Farivar, 1992) studied the benefits of learning in mixed groups. The researcher compared how much students with high, middle and low degrees of success have learned. The study concluded that learning in mixed-achievement groups helps to break down interpersonal barriers between high, middle and low achieving students. The students also acknowledge learning in small groups. I. Florez and M. McCaslin (Florez, McCaslin, 2008) have collected the students' perspectives on learning in small groups. The researchers concluded that students have a positive perspective on learning in small groups.

\section{Conclusions}

Small-group learning is a recommended teaching method and organizational form that should be included in the learning process. Before implementing this method in the classroom, it is important to understand the risks, which are mostly related to students` extreme expressions and reactions. For example, a student is not active in communicating with group members or dominates and fully subordinates the work of learning group to his/her interests and needs. In order to enable communication activity among the members in small-group, mutual trust and solidarity are required. It could be happening by asking for help from group members or/and offering support to other members. The study found that this factor affects the communication activity of each student in both unmixed-achievement groups and mixed-achievement groups. Besides asking for help or/and offering support there are other factors that could affect the communication activity of each primary school student. The study determined that the factors affecting communication activity could be different in unmixed- achievement groups and mixed-achievement groups. The communication activity in the mixed-achievement group is mostly associated with the opportunity to be creative and to give a significant contribution to the work of the group, but in the unmixed-achievement group, the communication activity is determined by fear from failure or orientation towards success. It was also found that the degree of success in the mixed-achievement group affects the progress towards the task being performed.

It is important in the learning group, not only to speak but also the ability to listen because the listening skill is much more than information perception by hearing organs. It is just as active communication as 
speaking, it requires concentration, mental activity and focusing on the other. It is an active engagement in the learning process. The study found that students' desire to listen more than speak in the mixedachievement group is related to subordination or dominance $(\mathrm{r}=0.408 ; \mathrm{p}<0,05)$, but in the unmixedachievement group, there were not found any significant affecting of speaking or listening.

A student's engagement in the mixed-gender group is related to activity or passivity. The student's activity in mixed-gender group is affected by factors such as the opportunity to be creative and to be a leader, who can control the situation, as well as the opportunity to give significant contribution to the work of group and to be oriented towards fulfilling a certain task successfully.

\section{Bibliography}

1. Bion W.R. (2004). Experiences in groups and other papers. London: Taylor and Francis e-Library. Retrieved from http://freudians.org/wp-content/uploads/2014/09/Wilfred-R.-Bion-Experiences-inGroups-and-other-papers-1991.pdf

2. Cambridge Dictionary. (2018). Cambridge: Cambridge University Press. Retrieved from https://dictionary.cambridge.org/dictionary/english/activity

3. Corsini R.J., Auerbach A.J. (1998). Concise Encyclopedia of Psychology. (2 ${ }^{\text {nd }}$ ed.). Canada: John Wiley and Sons.

4. Dewey J. (2015). Democracy and Education: An Introduction to the Philosophy of Education. New York: BiblioBazaar.

5. Engeström Y. (1987). Learning by Expanding: An Activity Theoretical Approach to Developmental Research. Helsinki: Orienta-Konsultit. Retrieved from http://lchc.ucsd.edu/mca/Paper/Engestrom/Learning-by-Expanding.pdf

6. Enzyklopadie der Werte (Online-Encyclopedia of Values). (2018). Hurth: DA VINCI $3000 \mathrm{GmbH}$. Retrieved from https://www.wertesysteme.de/aktivit\%C3\%A4t/ (in German)

7. Farivar S. (1992). Middle School Math Students`Reactions to Heterogeneous Small Group Work: They Like It! Paper presented at the annual meeting of the American Educational Research Association, San Francisco, CA.

8. Feygenberg I.M. (2014). Uchimsja vsyu zhizn (Lifelong learning). Moskva: Smysl. (in Russian)

9. Fisher R. (2014). Teaching children to learn. ( $2^{\text {nd }}$ ed.). New York, NY: Oxford University Press.

10. Florez I.R., McCaslin M. (2008). Student Perceptions of Small-Group Learning. Teachers College Record, 110 (11), 2438-2451.

11. Fredricks J.A. (2014). Eight Myths of Student Disengagement: Creating Classrooms of Deep Learning. Los Angeles: Corwin.

12. Gillies R. (2003). Structuring cooperative group work in classrooms. International Journal of Educational Research, 39 (1-2), 35-49.

13. Gillies R.M. (2004). The Effects of Cooperative Learning on Junior High School Students during Small Group Learning. Learning and Instruction, 14 (2), 197-213.

14. Gillies R.M., Boyle M. (2010). Teachers` Reflections on Cooperative Learning: Issues of Implementation. Teaching and Teacher Education, 26 (4), 933-940.

15. Harper D. (2010). Online Etymology Dictionary. Retrieved from https://www.etymonline.com/word/activity

16. Leontyev A.N. (2009). Activity and Consciousness. Pacifica, CA, USA: Marxists Internet Archive. Retrieved from https://www.scribd.com/document/168438828/Activity-and-ConsciousnessAleksei-Nikolaevich-Leontiev

17. Robinson M., Davidson G. (Eds.). (1999). Chambers $21^{\text {st }}$ Century Dictionary. Edinburg, Great Britain: Chambers.

18. Schellenberg E.G., Corrigall K.A., Dys S.P., Malti T. (2015). Group Music Training and Children`s Prosocial Skills. PLOS ONE, 10(10). Retrieved from http://journals.plos.org/plosone/article?id=10.1371/journal.pone.0141449

19. Shachar H., Fischer S. (2004). Cooperative learning and the Achievement of Motivation and Perceptions of Students in 11h Grade Chemistry Classes. Learning and Instruction, 14 (1), 69-87.

20. Webb N. (2009). The Teacher`s Role in Promoting Collaborative Dialogue in the Classroom. British Journal of Educational Psychology, 79 (1), 1-28. 